\title{
APLIKASI ANALISIS NETWORK FORENSIC UNTUK ANALISIS SERANGAN PADA SYSLOG SERVER
}

\author{
I Wayan Ardiyasa \\ Institut Teknologi dan Bisnis STIKOM Bali/Sistem Informasi; Jl. Raya Puputan, No.86 Renon \\ Denpasar Bali, (0361) 244445 \\ Jurusan Sistem Informasi, Fakultas Informatika dan Komputer, ITB STIKOM Bali, Bali. \\ e-mail: ardi@stikom-bali.ac.id
}

\begin{abstract}
Abstrak-Perkembangan internet saat ini tidak lepas dari perkembangan teknologi yang semakin canggih sehingga menjadikan akses informasi semakin mudah dan cepat. Informasi yang diakses oleh pengguna disediakan oleh layanan komputer server yang bisa memberikan layanan secara full time. Aktivitas pengguna yang mengkases informasi pada suatu server akan dicatat kedalam sebuah file atau disebut dengan Syslog. Syslog adalah perangkat lunak untuk menghasilkan berkas log yang disebabkan adanya aktivitas dari Inetd dan aktivitas lain. Tujuan dicatatnya aktivitas dari pengguna yang mengakses sistem informasi yang tersimpan pada komputer server adalah untuk mengetahui apabila ada aktivitas yang tidak sesuai atau kejahatan cyber seperti DDoS, SQL Injection, Serangan LFI, RFI. Network Forensic Process merupakan suatu metode yang dapat digunakan untuk kegiatan investigasi dan analisa aktivitas cyber crime. Dimana bukti ditangkap dari jaringan dan diinterpretasikan berdasarkan pengamatan. Didalam melakukan investigasi terhadap Syslog file dilakukan secara manual sehingga memerlukan waktu yang sangat lama dan tidak efisien. Untuk membantu didalam melakukan analisa dan investigasi terhadap Syslog file dari kejahatan cyber, diperlukan aplikasi yang bisa membantu dalam hal investigasi Syslog file untuk mempercepat proses investigasi dan memberikan informasi yang diperlukan dan akurat. Hasil dari penelitian ini adalah aplikasi analisa serangan pada file Syslog dengan metode Network Forensic Proses. Untuk pengujian pada aplikasi menggunakan metode Blackbox testing.
\end{abstract}

Kata kunci-Network Forensic, Syslog, Cyber crime, Investigasi.

\section{PENDAHULUAN}

Perkembangan internet saat ini tidak lepas dari perkembangan teknologi yang semakin canggih sehingga menjadikan akses informasi semakin mudah dan cepat. Informasi yang diakses oleh pengguna melalui media internet dengan penyedia layanan dari komputer server yang mampu memberikan layanan secara real time dan full time. Aktivitas dari pengguna yang mengakses informasi pada suatu server akan dicatat kedalam sebuah layanan atau disebut dengan File Syslog. Syslog adalah perangkat lunak untuk menghasilkan berkas log yang disebabkan adanya aktivitas dari Inetd dan aktivitas lain [1]. Syslog server adalah sebuah server yang menyimpan data Syslog berbagai macam perangkat komputer dan jaringan secara terpusat[2]. Syslog server harus memiliki ketersediaan tinggi untuk melayani penyimpanan syslog setiap perangkat komputer dan jaringan [3][4]. Tujuan dicatatnya aktivitas dari pengguna yang mengakses informasi yang tersimpan pada komputer server adalah untuk mengetahui apabila ada aktivitas atau kegiatan yang tidak sesuai atau kejahatan cyber seperti serangan $D D o S, S Q L$ Injection, Serangan LFI, XSS. Data syslog tersebut digunakan sebagai barang bukti apabila adanya insiden yang dapat merugikan dari sisi penyedia.
Adapun informasi yang dapat dianalisa seperti informasi tentang jenis serangan yaitu informasi $I P$ Address, informasi Waktu dan tanggal akses dan informasi url yang diakses serta kegiatan yang dilakukan didalam komputer server.

Untuk mendapatkan informasi serangan pada sebuah komputer server perlu dilakukannya analisis terhadap file syslog. Metode yang digunakan didalam melakulan analisis adalah metode Network forensic process[5]. Network Forensic Process merupakan suatu metode yang dapat digunakan untuk kegiatan investigasi dan analisa aktivitas cyber crime. Dimana bukti ditangkap dari jaringan dan diinterpretasikan berdasarkan pengamatan [6][7]. Kebanyakan tim investigasi digital forensic didalam melakukan investigasi terhadap file syslog dilakukan secara manual dengan memeriksa isi file syslog perbaris kode, sehingga memerlukan waktu yang sangat lama untuk menemukan sumber dan informasi serangan dari file syslog tersebut. Untuk membantu investigator didalam melakukan analisa dan investigasi terhadap file syslog dari kejahatan cyber, perlu adanya aplikasi yang bisa membantu dalam kegiatan investigasi terhadap file syslog yang bertujuan untuk membantu mempercepat 
proses investigasi dan memberikan informasi yang diperlukan secara baik dan akurat.

Penelitian ini menghasilkan aplikasi untuk melakukan analisa serangan cyber terhadap suatu komputer sistem pada file syslog.

\section{LANDASAN TEORI}

\subsection{Syslog}

Syslog adalah mekanisme audit gabungan yang digunakan oleh sistem operasi Linux. Ini memungkinkan pengumpulan log lokal dan jarak jauh. Syslog memungkinkan administrator sistem untuk mengumpulkan dan mendistribusikan data audit dengan satu titik manajemen. Syslog dikendalikan berdasarkan per-mesin dengan file /etc/syslog.conf [8]. Syslog adalah perangkat lunak untuk menghasilkan berkas log yang disebabkan adanya aktivitas dari Inetd dan aktivitas lain [1]. Syslog server adalah sebuah server yang menyimpan data syslog berbagai macam perangkat komputer dan jaringan secara terpusat. Syslog server harus memiliki ketersediaan tinggi untuk melayani penyimpanan syslog setiap perangkat komputer dan jaringan [3].

\subsection{Network Forensic}

Network forensics adalah meng-capture, merekam, dan menganalisis kejadian didalam jaringan untuk menemukan sumber serangan keamanan. Menangkap lalu lintas jaringan melalui jaringan itu sederhana secara teori, tetapi dalam praktiknya relatif kompleks. Ini dikarenakan besarnya jumlah data yang mengalir melalui jaringan dan sifat kompleks dari protokol Internet[8] atau Network Forensic Process merupakan suatu metode yang dapat digunakan untuk kegiatan investigasi dan analisa aktivitas cyber crime. Dimana bukti ditangkap dari jaringan dan diinterpretasikan berdasarkan pengamatan[6]

\section{METODE}

Pada penelitian ini mengadopsi dan menggunakan metode Network Forensic Process. Network Forensic adalah meng-capture, merekam, dan menganalisis kejadian didalam jaringan untuk menemukan sumber serangan keamanan. Menangkap lalu lintas jaringan melalui jaringan itu sederhana secara teori, tetapi dalam praktiknya relatif kompleks. Ini dikarenakan besarnya jumlah data yang mengalir melalui jaringan dan sifat kompleks dari protokol Internet[8] atau Network Forensic Process merupakan suatu metode yang dapat digunakan untuk kegiatan investigasi dan analisa aktivitas cyber crime. Dimana bukti ditangkap dari jaringan dan diinterpretasikan berdasarkan pengamatan[6]. Ada beberapa langkah didalam melakukan investgasi. Metode ini digunakan untuk mendapatkan informasi dan mengambil keputusan[9]. Tahapan pada penelitian ini dapat digambarkan seperti pada Gambar 1.

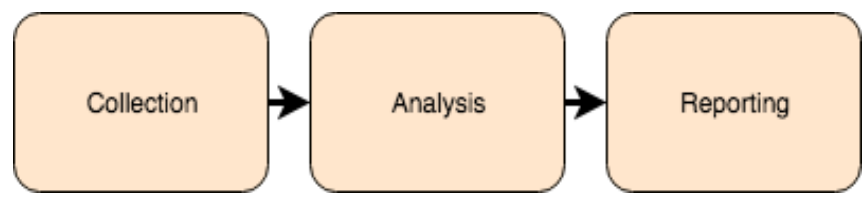

Gambar 1. Network Forensic Process

Tahapan Network Forensic Process dibagi menjadi tiga proses diantaranya Collection, Analysis dan Reporting. Pada Gambar 1, tahap network forensic Process dapat dijelaskan bahwa metode tahap Network Forensic dimulai dengan Collection atau disebut pengumpulan paket data di jaringan internet[10]. Pada tahap ini pengumpulan data dilakukan secara online (data bersifat volatile) data yang diambil adalah file syslog yang diambil pada webserver komputer server dengan file type .log. Tahap berikutnya adalah Analysis, pada tahap analysis investigator melakukan analisa terhadap file syslog untuk mencari informasi serangan cyber terhadap komputer server yang tercatat oleh syslog. Jenis serangan yang dianalisa adalah serangan SQL Injection, XSS dan LFI. Tahap akhir adalah Reporting. Reporting adalah tahap pelaporan dari hasil analisis dari file syslog dengan format file .pdf.

\section{HASIL}

\subsection{Arsitektur Sistem}

Aplikasi ini merupakan aplikasi berbasis web dengan arsitektur sistem menggunakan localhost untuk menjalankan proses aplikasi ini selain itu, penggunaan report dan database digunakan sebagai media untuk menyimpan proses analisa yang dilakukan oleh investigator dan modul report untuk menampilkan hasil dari analisa tersebut. Berikut ini merupakan arsitektur sistem pada aplikasi analisa file syslog menggunakan metode Network forensic proses pada gambar 2.

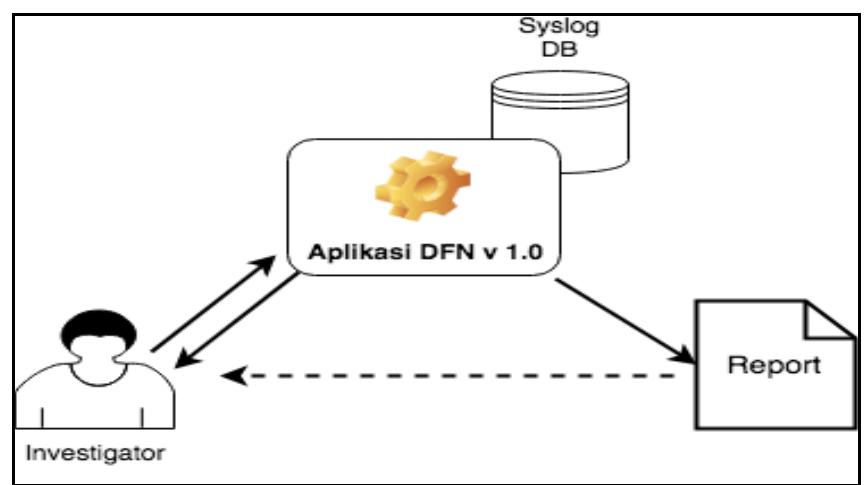

Gambar 2. Arsitektur Sistem Aplikasi analisis file syslog

Arsitektur sistem pada gambar 2. Merupakan gambaran umum dari aplikasi analisa file Syslog berbasis web. Pada aplikasi terdapat satu pengguna yaitu pengguna 
sebagai investigator. Investigator merupakan sebutan untuk ahli dibidang digital forensic. Untuk melakukan analisa file Syslog, investigator mengakses aplikasi dengan membuat dan menginputkan terlebih dahulu nama investigator dan kasus yang terjadi pada file syslog. File syslog diupload dan dilakukan analisis dengan cara mengupload dan membuka file syslog serta ditampilkan pada halaman aplikasi analisis tersebut. Untuk melakukan analisis, investigator menggunaka sistem filtering dengan cara menginputkan jenis serangan yang terjadi pada file syslog tersebut. Jenis serangan tersebut seperti SQL Injection (sqli), Cross Site Srcipting (XSS) dan Local File Inclusion (lfi). Dengan menggunakan sistem filter, investigator langsung dapat mengetahui informasi jenis serangan, sumber serangan berupa IP Address, waktu serangan dan titik kelemahan dari sistem tersebut. Setelah melakukan analisis file syslog dan apabila didapatkan informasi serangannya langkah berikutnya adalah dilakukan proses cetak. Proses cetak akan menghasilkan report dari informasi investigator dan informasi serangannya secara detail dan report yang dihasilkan dari aplikasi ini bisa digunakan sebagai barang bukti di pengadilan untuk kasus kejahatan komputer.

\subsection{Perancangan Sistem}

Didalam membangun dan merancang aplikasi analisis network forensic file syslog menggunakan Diagram konteks, Data Flow Diagram serta menggunakan konseptual database dan ERD untuk menggambarkan struktur rancangan databasenya. Berikut ini adalah rancangan dan aliran data pada aplikasi network forensic file syslog adalah sebagai berikut :

\subsubsection{Diagram Konteks}

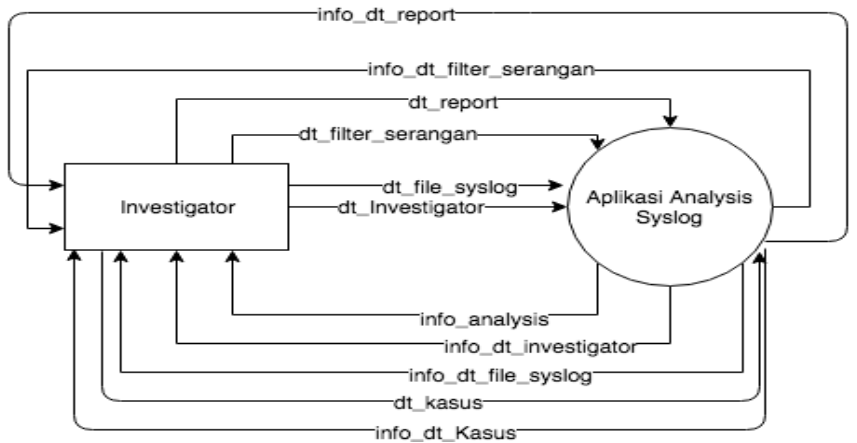

Gambar 3. Diagram Konteks Aplikasi analisis syslog

\subsubsection{DFD Level 0}

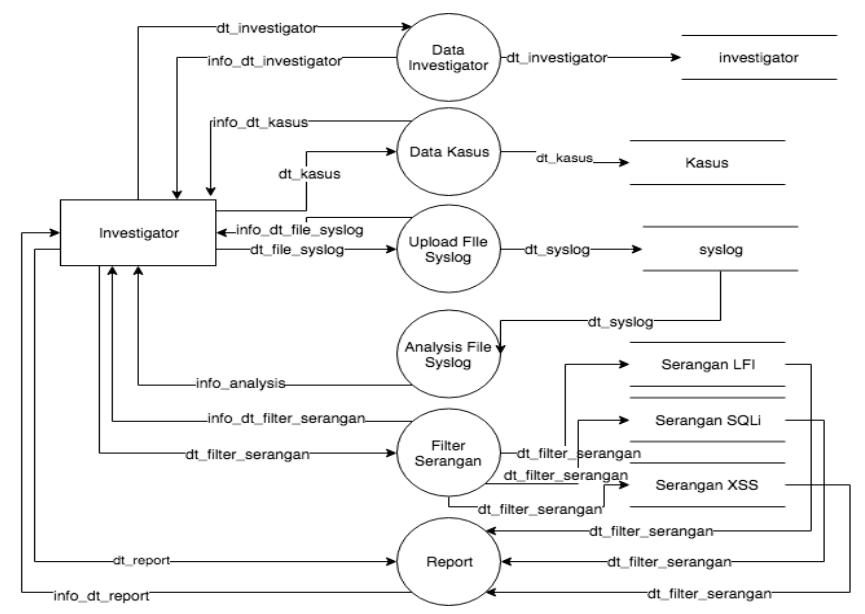

Gambar 4. DFD level 0 Aplikasi analisis file syslog

\subsubsection{Konseptual Database}

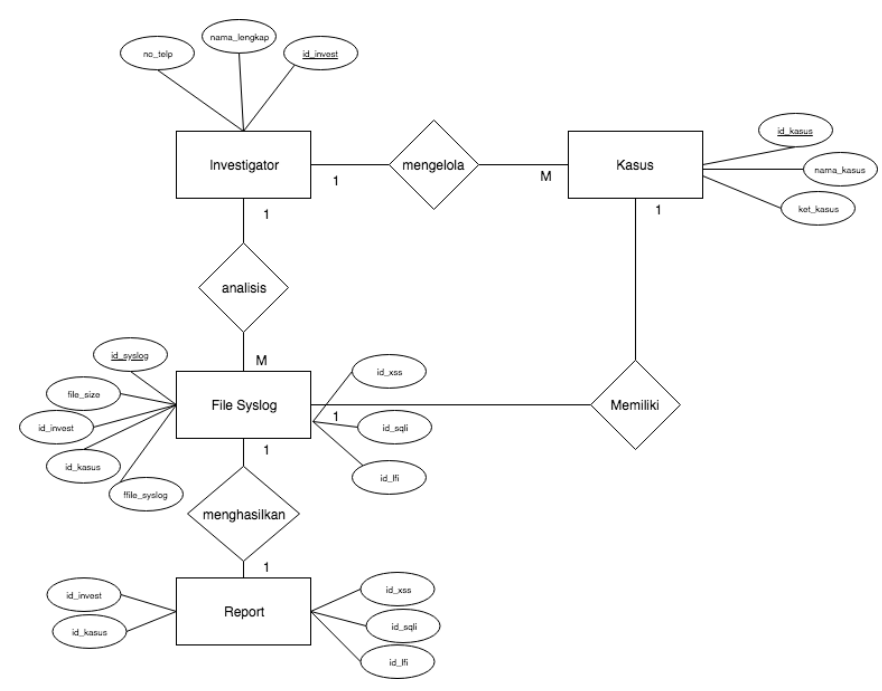

Gambar 5. Konseptual Database

\subsubsection{ERD}

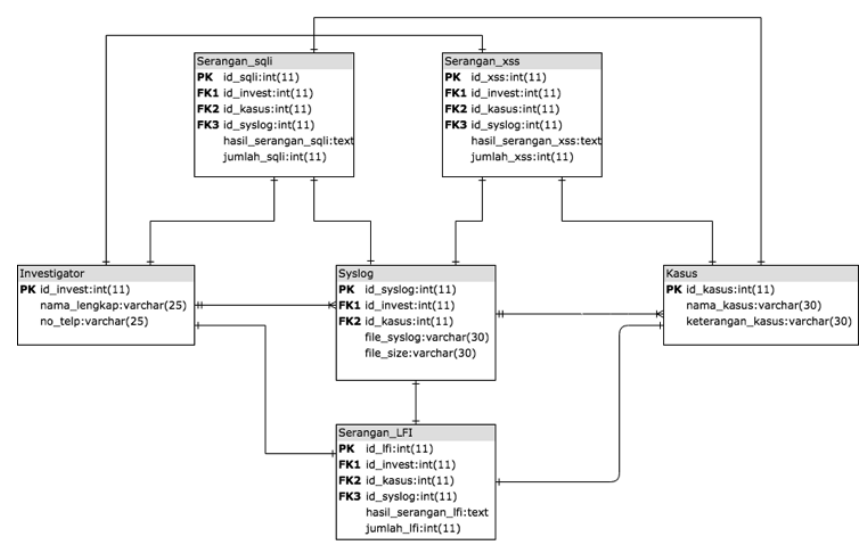

Gambar 6. Entity Relationship Diagram (ERD) 


\subsection{Implementasi Sistem}

4.3.1 Antarmuka aplikasi halaman home

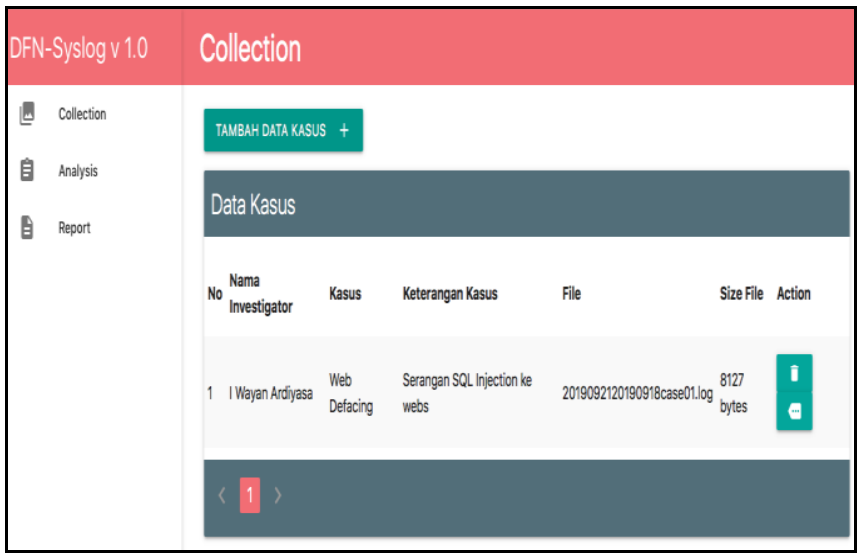

Gambar 7. Halaman home aplikasi analysis file syslog

4.3.2 Antarmuka aplikasi halaman data kasus dan input data investigator

\begin{tabular}{|c|c|}
\hline DFN-Syslog v 1.0 & Collection \\
\hline E collection & \\
\hline 自 Anaysis & Input Data Investigator \\
\hline - R Report & $\boldsymbol{\theta}$ I Wayan Arcivasa \\
\hline & Cosi80888000 \\
\hline & saren kens \\
\hline & $\mathrm{T}$ Web Defacing \\
\hline & 日. Tejadad insiden web defacing pada situs $x y z$.com \\
\hline & 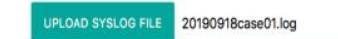 \\
\hline & SIMPAN DATA $\checkmark$ \\
\hline
\end{tabular}

Gambar 8. Halaman input data investigator

\subsubsection{Antarmuka aplikasi halaman analysis kasus}

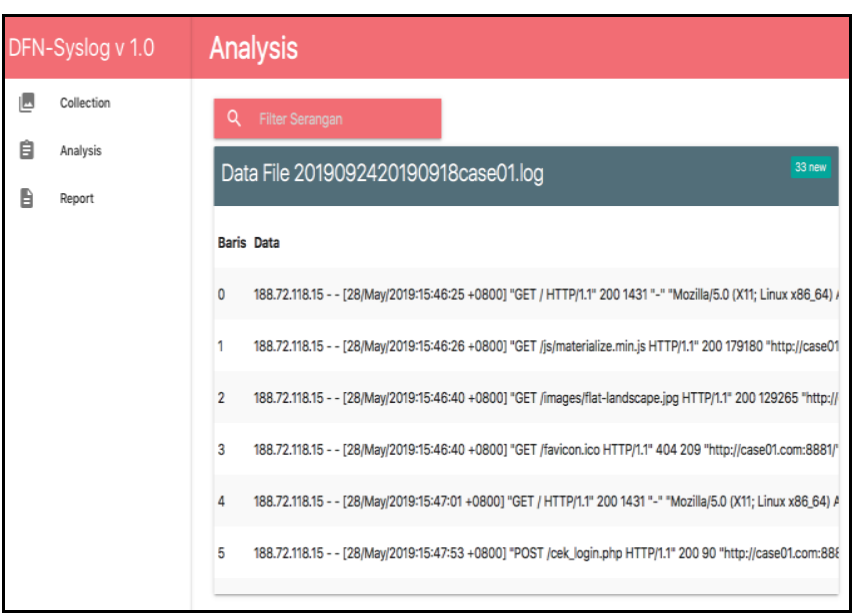

Gambar 9. Halaman analysis serangan cyber

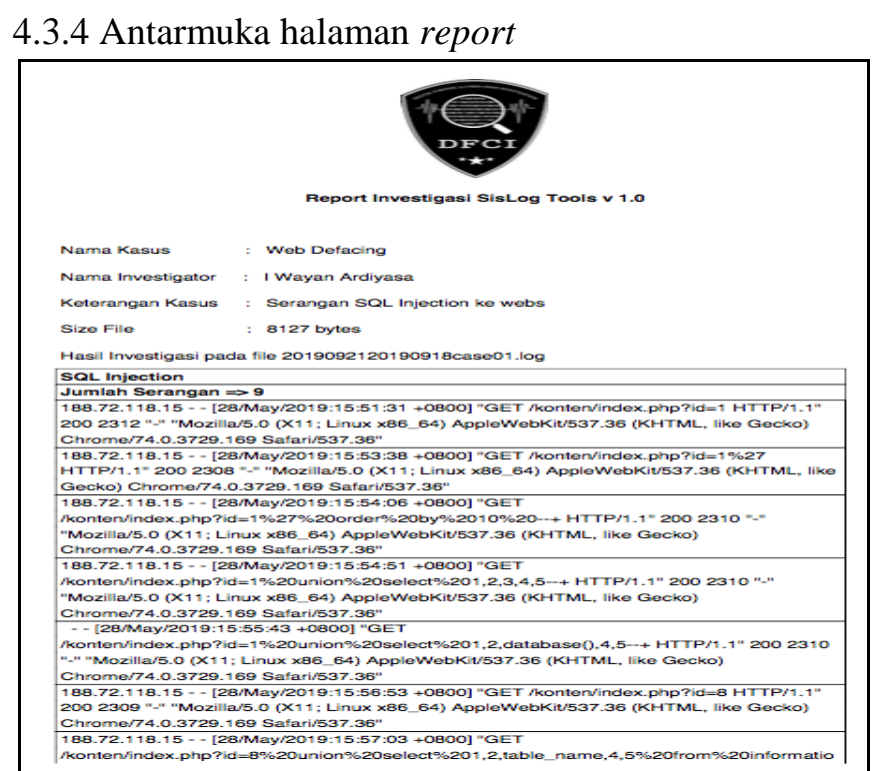

Gambar 10. Report hasil analisis serangan

\subsection{Pengujian}

Pengujian dilakukan untuk mengukur kesesuaian rancangan dan implementasi serta untuk mengetahui kesalahan atau error yang mungkin terjadi pada aplikasi. Pengujian dilakukan dengan menggunakan metode blackbox testing. Metode blackbox testing merupakan pengujian yang berfokus terhadap fungsionalitas dari aplikasi analisa network forensic file syslog. Berikut tabel hasil pengujian metode blackbox testing pada aplikasi analisis network forensic file syslog adalah sebagai berikut :

Tabel 1. Tabel hasil pengujian blackbox testing pada aplikasi

\begin{tabular}{|c|c|c|c|c|}
\hline No. & $\begin{array}{c}\text { Skenario } \\
\text { Testing }\end{array}$ & $\begin{array}{l}\text { Hasil yang } \\
\text { diharapkan }\end{array}$ & $\begin{array}{c}\text { Hasil } \\
\text { Pengujian }\end{array}$ & Keterangan \\
\hline 1. & $\begin{array}{l}\text { Menginputkan } \\
\text { semua isian } \\
\text { data kasus dan } \\
\text { isian data } \\
\text { investigator, } \\
\text { lalu pilih file } \\
\text { syslog dan klik } \\
\text { button } \\
\text { 'simpan' }\end{array}$ & $\begin{array}{l}\text { Sistem } \\
\text { menampilkan } \\
\text { messagebox } \\
\text { data sudah } \\
\text { disimpan }\end{array}$ & $\begin{array}{c}\text { Sesuai } \\
\text { harapan }\end{array}$ & Valid \\
\hline 2. & $\begin{array}{l}\text { Mengosongkan } \\
\text { semua isian } \\
\text { data pada } \\
\text { halaman } \\
\text { tambah data } \\
\text { kasus dan data } \\
\text { investigator, } \\
\text { lalu kilk button } \\
\text { 'simpan' }\end{array}$ & $\begin{array}{l}\text { Sistem } \\
\text { menampilkan } \\
\text { 'gagal!tipe } \\
\text { file tidak } \\
\text { sesuai' }\end{array}$ & $\begin{array}{l}\text { Sesuai } \\
\text { harapan }\end{array}$ & Valid \\
\hline 3. & $\begin{array}{l}\text { Menghapus } \\
\text { data kasus }\end{array}$ & $\begin{array}{l}\text { Sistem } \\
\text { menampilkan }\end{array}$ & $\begin{array}{c}\text { Sesuai } \\
\text { harapan }\end{array}$ & Valid \\
\hline
\end{tabular}




\begin{tabular}{|c|c|c|c|c|}
\hline No. & $\begin{array}{c}\text { Skenario } \\
\text { Testing }\end{array}$ & $\begin{array}{l}\text { Hasil yang } \\
\text { diharapkan }\end{array}$ & $\begin{array}{c}\text { Hasil } \\
\text { Pengujian }\end{array}$ & Keterangan \\
\hline & 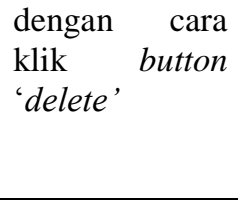 & $\begin{array}{l}\text { messagebox } \\
\text { 'Yakin mau } \\
\text { dihapus?' } \\
\text { klik OK data } \\
\text { terhapus }\end{array}$ & & \\
\hline 4. & \begin{tabular}{lr}
\multicolumn{2}{l}{ Melakukan } \\
analisa file \\
syslog, dengan \\
cara rlik \\
button analisis \\
file
\end{tabular} & $\begin{array}{l}\text { Sistem } \\
\text { menampilkan } \\
\text { halaman } \\
\text { analisa file } \\
\text { syslog }\end{array}$ & $\begin{array}{c}\text { Sesuai } \\
\text { harapan }\end{array}$ & Valid \\
\hline 5 . & $\begin{array}{l}\text { Melakukan } \\
\text { filtering } \\
\text { serangan untuk } \\
\text { mengetahui } \\
\text { jenis serangan } \\
\text { yang ada pada } \\
\text { file syslog, } \\
\text { langkahnya } \\
\text { menggunakan } \\
\text { keyword sqli, } \\
\text { lfi, xss pada } \\
\text { filter pencarian } \\
\text { lalu lanjutkan } \\
\text { dengan enter. }\end{array}$ & $\begin{array}{l}\text { Sistem } \\
\text { menampilkan } \\
\text { infornasi } \\
\text { yang dicari } \\
\text { oleh } \\
\text { investigator }\end{array}$ & $\begin{array}{l}\text { Sesuai } \\
\text { harapan }\end{array}$ & Valid \\
\hline 6. & $\begin{array}{l}\text { Mencetak hasil } \\
\text { analisa kasus } \\
\text { dalam bentuk } \\
\text { report, } \\
\text { langkahnya } \\
\text { klik button } \\
\text { 'report' }\end{array}$ & $\begin{array}{l}\text { Sistem } \\
\text { menampilkan } \\
\text { report dalam } \\
\text { bentuk pdf }\end{array}$ & $\begin{array}{c}\text { Sesuai } \\
\text { harapan }\end{array}$ & Valid \\
\hline
\end{tabular}

ini bisa digunakan oleh investigator untuk proses hukum apabila diperlukan.

\section{KESIMPULAN}

Adapun kesimpulan dari penelitian ini adalah :

1. Telah dihasilkannya aplikasi analisis file syslog untuk melakukan analisa serangan kedalam komputer server berbasis web.

2. Perancangan aplikasi analisis file syslog menggunakan Data Flow Diagram, konseptual database dan entity relationship diagram.

3. Pada tahap pengujian aplikasi menggunakan metode blackbox testing untuk mengetahui kesesuaian fungsionalitas aplikasi. Hasil dari pengujian ini sudah sesuai harapan dan valid.

\section{DAFTAR PUSTAKA}

[1] I. Mahardika, "Secure remote login pada sistem operasi slackware linux," hal. 1-7, 2003.

[2] L. B. Becker, M. Gergeleit, S. Schemmer, dan E. Nett, "Using a flexible real-time scheduling strategy in a distributed embedded application," in IEEE International Conference on Emerging Technologies and Factory Automation, ETFA, 2003, vol. 2, no. January, hal. 652-657.

[3] T. H. Ditanaya, R. M. Ijtihadie, dan M. Husni, "Rancang Bangun Sistem Log Server Berbasis Syslog dan Cassandra untuk Monitoring Pengelolaan Jaringan di ITS," J. Tek. ITS, vol. 5, 2016.

[4] E. K. Dewi, "ANALISIS LOG SNORT MENGGUNAKAN NETWORK FORENSIC," JIPI (Jurnal Ilm. Penelit. dan Pembelajaran Inform., vol. 2, no. 2, Des 2017.

\subsection{Pembahasan}

Hasil pada tahap implementasi dan pengujian yang dilakukan sudah sesuai dengan yang diharapkan. Aplikasi analisis network forensic untuk melakukan analisa serangan cyber pada file syslog bertujuan untuk membantu khususnya investigator digital forensic didalam mencari informasi serangan cyber pada file syslog. Aplikasi ini dibuat berbasis web untuk bisa diakses oleh pengguna lainnya apabila ingin melakukan analisa awal terhadap kasus kejahatan cyber. File syslog didapakan dari teknik collection secara online, setelah didapatkan file syslog.log dilakukan tahap analisa dengan melakukan input data investigator dan file syslog.log yang akan dianalisa. Pada tahap analisa, investigator bisa melakukan analisa serangan dengan menggunakan sistem filtering untuk mencari informasi serangan pada file syslog.log paramete jenis serangan yang bisa dicari adalah SQLinjection, XSS dan LFI. Apabila ditemukan adanya serangan maka investigator bisa melakukan proses reporting atau pelaporan dari hasil investigasi untuk dukumentasi dan hasil pelaporan
M. N. A. Khan, "Multi-agent Based Forensic Analysis Framework for Infrastructures Involving Storage Networks," Proc. Natl. Acad. Sci. India Sect. A - Phys. Sci., vol. 89, no. 2, hal. 291-309, Jun 2019.

[6] A. Ginanjar, N. Widiyasono, dan R. Gunawan, "Analisis Serangan Web Phishing pada Layanan Ecommerce dengan Metode Network Forensic Process," JUTEI Ed. Vol. No.2 Oktober 2018, no. 2, hal. 147-157, 2018.

[7] A. Al-murjan, "Network Forensic Investigation of Internal Misuse / Crime in Saudi Arabia : A Hacking Case," Annu. ADFSL Conf. Digit. Forensics, Secur. Law, no. Gollmann 2006, hal. 15-32, Okt 2008.

[8] EC-Council, Investigating Network Intrusions and Cybercrime. 2010.

[9] A. Lubis, A. Putera, dan U. Siahaan, "NetworkForensic Application in General Cases," IOSR J. Comput. Eng., vol. 18, no. December, hal. 41-44, 2016.

[10] I. Riadi dan N. Hildayanti, "Forensics Analysis of Router On Computer Networks Using Live Forensics Method," Int. J. Cyber-Security Digit. Forensica 8(1) 74-81, no. May, 2019. 